\title{
Does compatibility of personality affect productivity? An exploratory study with construction crews
}

\author{
Laura Florez, Ph.D. ${ }^{1}$ (Corresponding Author), Phillip Armstrong² and Jean C. Cortissoz, Ph. D³.
}

${ }^{1}$ Lecturer, Bartlett School of Construction and Project Management, University College London, London, WC1E 7HB, UK;

email: 1.florez@ucl.ac.uk

${ }^{2}$ Quantity Surveyor, Costain Group, Ingwell Hall, Moor Row, Cumbria, CA24 3JZ, UK.; email:

phillip.armstrong@costain.com

${ }^{3}$ Associate Professor, Department of Mathematics, Universidad de los Andes, Bogota, 111711, Colombia; email:

jcortiss@uniandes.edu.co

Crew productivity is a function of how efficiently labor is utilized in the construction process. However, previous research in construction has not comprehensively investigated the relationship between personality and crew productivity. This paper uses personality profiles to investigate a new fundamental concept, the relationship between compatibility of personality and crew productivity at the task level. Twenty-eight masons completed a revised questionnaire of the big five to indicate their personality. Personality scores were used to calculate compatibility in each of the 20 participating two-mason crews working on eight projects. Regression analysis was performed to establish the relationship between compatibility and crew productivity. Results show that that there is a high positive correlation between compatibility and crew productivity. Compatibility accounts for more than half of the predictable variance in productivity. This paper makes four major contributions: it proposes a new metric to measure compatibility of personality among workers in a crew; it reveals how personality factors affect productivity; it provides rigorous methods to analyse correlations (using confidence intervals and Bayesian inference) for construction experiments; and it provides theoretical contributions to advancing the theory of personality and productivity in construction projects.

Keywords: crew management; productivity; personality; compatibility; correlation analysis

\section{Introduction}

Crew productivity is a function of how efficiently labor is used in the construction process and it is key to the success of any project. Various factors affect crew productivity such as the work environment (Ailabouni et al, 2007), project characteristics (Sanders and Thomas, 1991), resources (Thomas and Sudhakumar, 2013), management (Chih et al, 2017), and motivation (Raoufi and Robinson Fayek, 2018). Human factors and the interrelationship between the workers in a crew also affect 
productivity (Dozzi and AbouRizk, 1993). Workers have many distinct personality characteristics and when working in crews the mix or combination of personality influences group performance (Culp and Smith, 2001). It is expected that workers that have compatible personalities will be more productive. However, the actual relationship between compatibility and productivity has not been tested and assessed in real live construction projects.

In labor-intensive projects such as masonry, masons must coordinate when to raise the line in a wall and often perform interdependent work, in that they depend on each other for completing tasks (Mitropoulos and Memarian, 2012). A course in a wall (vertical line) has to be finished before masons can continue building another course (horizontally). This results in constant interactions between the masons in a crew, as it requires good synchronization (no mason can continue placing units until the line is finished) and timing. Therefore, it is of interest to study crew interactions in masonry given that it requires team work. The capability of the masons to work together as a team and achieve high production rates might be enhanced or hindered by the adequate mix or combination of personality characteristics. Therefore, when studying the impact of compatibility and crew productivity, it is important to consider personality.

Personality is a psychological construct often used to describe the structures, dynamics, and tendencies that bring about behaviours and attitudes in individuals (Hofmann and Jones, 2005). The personality of individuals is usually described in five dimensions $(\mathrm{O}=$ openness, $\mathrm{C}=$ conscientiousness, $\mathrm{E}=$ extroversion, $\mathrm{A}=$ agreeableness, and $\mathrm{N}=$ neuroticism $)$ in a widely accepted theory among psychologists (Gosling et al, 2003; Maltby et al, 2017). When individuals are grouped in teams, their personalities combine, and the establishment of teams is consistent with a psychological approach. The rationale of this approach is to structure teams to increase related outcomes (Campion et al, 1993). Consequently, the challenge for a manager in assigning individuals to teams is to consider their personality in such a way that will help the team achieve a high performance (Culp and Smith, 2001; Regans et al, 2004). If it is expected that workers that have compatible personalities tend to have a high performance, a manager would need to staff teams with an adequate combination of personalities as the team has the potential to be highly productive.

In construction, some studies have identified personal characteristics in crews that contribute to performance. Characteristics such as cohesion (Chih et al, 2017), motivation (Raoufi and Robinson Fayek, 2018), affection (Mitropoulos and Memarian, 2012), cooperation (Dozzi, and AbouRizk, 1993), good relations (Kazaz et al, 2008), trust (Wu et al, 2017), team spirit and integration (Thomas and Sudhakumar, 2013; Naoum, 2016), behaviour (Liu et al, 2019), people skills (Atalah, 2019), and stability (Kwofie et al, 2015) have shown to positively affect performance of construction crews. Other studies have gone further and investigated the effect of personal factors on performance. Such factors include personal confidence (Castillo et al, 2018), job satisfaction (Wang et al, 2020), self-organizing and sense-making properties (Sprauer et al, 2016). Personality and 
psychological constructs and their effects on teams and organisations have been studied in relation to retention processes (Childs et al, 2017), turnover intention (Wang et al, 2020), commitment (Chih, 2017), satisfaction and trust (Chow et al, 2015), and culture and climate (Domingues Quelhas et al, 2019). More recently Li et al (2019) provided a review on characteristics including attitude, job satisfaction, motivation, and personality among others that should receive more attention in the context of individual and organizational behaviors in the field of management.

However, to the best of the authors' knowledge, research that clearly determines and quantifies the relationship between personal compatibility and crew productivity has yet to be undertaken in the construction field and with real life projects. The effect of personality on productivity has not been investigated in previous construction studies. When investigating factors that influence crew productivity, technical factors such as skills, capabilities, experience, and qualifications of the workers in a crew can be considered. These technical factors typically have a low variation among the masons in a crew (Florez, 2017), that is, we can assume that a mason has the minimum skills (knows how to lay masonry units), qualifications (can work in different wall sections and wall complexities), has experience (minimum years) and training background (training in the masonry trade). As productivity has a high variability, it can supposed there are other factors that can explain such variability and that are not evident or have not been studied previously. One of such factors is personality. Personality and the mix of personalities have a high variation among the masons in a crew so it is of interest to establish its effect on productivity. This study has three objectives: 1) to propose a metric to measure compatibility of personality between the workers in a crew; 2 ) to investigate the true impact of compatibility on productivity in a field setting with real life projects; and 3) to provide rigorous statistical analyses for experiments in construction and advance theories of personality and productivity. This theories will

To develop these objectives, this paper is organized as follows. The next section presents the research questions, methodology, and hypothesis. Next, the proposed model of the relationship between productivity and compatibility (and its components) is described. Calculations of compatibility and productivity measures are presented alongside a series of statistical analyses which include correlation, confidence intervals, and Bayesian inference. Finally, the last section discusses the results, concludes the paper, and provides opportunities for future research.

\section{Research Questions and Methodology}

In this paper, personality and its associated measures are identified using the big five dimensions of personality. This paper seeks to answer the following research question: Does greater compatibility of personality between the masons in a crew leads to higher productivity? In order to answer this question, a model of the relationship between personality factors, compatibility, and productivity was proposed. An adapted questionnaire of the big five personality test was administered to a group of 
subcontracted masons working in house building projects across the UK. Based on the results of the questionnaire, the personality profiles were determined for twenty-eight masons and a compatibility metric between the masons in a crew was calculated for each crew. For each of the 20 participating two-mason crews, productivity metrics were collected on a weekly basis for 16 consecutive weeks on eight live projects. Crew productivity is defined as the ratio between the overall output and productive time. The collected data were used for data analysis because it included the full set of personality dimensions of the masons, which allowed calculating the compatibility of the crews. Productivity metrics were gathered from the field using the single-factor task-level productivity method, that is, productivity at the operational level on-site. Data analysis was performed to investigate the relationship between compatibility of personality and productivity at the crew level. The analytical results alongside methods for calculating confidence intervals and Bayesian inference are presented.

\section{Statistical analyses}

To determine if there is a relationship between productivity and compatibility of personality, a series of statistical analyses were performed (see Fig. 1). In step 1, the hypothesis was established, that is, to determine whether greater compatibility of personality between the masons in a crew leads to higher productivity. The null and alternative hypotheses were stated. A correlation analysis was performed to assess the relationship between compatibility and productivity. First, the Spearman analysis was used to assess the correlation between the five factors of personality. Both the strength and direction of the relationships were determined for each pair. Second, the Spearman analysis was performed to determine the correlation between compatibility and productivity. A one-tailed test was conducted to test the null hypothesis and a correlation coefficient was obtained. The coefficient determined the correlation between compatibility and productivity. In step 2, a further analysis was conducted to establish confidence intervals. The analysis on confidence intervals was developed with the purpose of determining how good the correlation coefficient (obtained in step 1) reflects the behavior of the whole population (in this case two-mason crews). With the correlation coefficient and the sample size, an estimator for the coefficient was determined. In step 3, a Bayesian inference test was performed. Bayesian inference gives the possibility of computing how much more likely is a hypothesis given the collected data. With this test, the probability that the correlation coefficient between compatibility and productivity was exactly (a given value) was calculated. The expected value for the coefficient was determined.

\section{[Insert Fig. 1 here]}

\section{Proposed model of the relationship between compatibility and crew productivity}

It has been stated by several researchers in the non-construction field that personality characteristics of the workers in a group affect group performance (Campion et al, 1993; Halfill et al, 2005; Peeters et al, 2006). Within the body of work on group 
personality composition, there are two personality orientations: the task orientation and relationship orientation (Halfill et al, 2005). In the case of task orientation, the focus is on personality traits that aid in the completion of work-related activities. In the case of relationship orientation, the focus is on personality traits that facilitate the interpersonal interactions necessary to work as a member of a team. The distinction of task and relationship orientation also impact criterion measures of performance. Task-oriented criteria measure components of group performance such as quality, quantity, and productivity. Relationship oriented criteria measure the social or relationship aspects of group effectiveness such as viability, empathy, and cohesion (Peeters et al, 2006).

This model focuses on the task-orientation perspective of performance. In other words, whether the combination of personality among the workers in the crew support the completion of the work and contribute to overall task performance. Task performance was measured using productivity performance and productivity metrics were collected for all crews at the task level. Note that other measures of performance such as those that contribute to relationships will not be considered in this study.

Fig. 2 shows the proposed model of compatibility of personality and crew productivity. The aim of this model is to investigate, for the first time in construction studies, the relationship between personality characteristics and crew productivity. Compatibility is the predictor variable in the model. Crew productivity is the dependent variable in the model. The personality factors are openness, conscientiousness, extraversion, agreeableness, and neuroticism (OCEAN); each of which operates at the workers' level. Personality factors identify personality profiles and operate at the individual level. Compatibility operates at the crew level as it focuses on the combination of personalities. Crew productivity is considered at the task level as it bodes well for exploring the relationship between performance and the mix of personalities at the crew level (compatibility). Note that this model focuses only on personality. Technical factors that may affect crew productivity in masonry, such as the skills and capabilities of the masons typically have a low variation (Florez, 2017). It is assumed that a mason has the minimum skills (knows how to lay masonry units) and capabilities (can work in wall sections of different complexities) in masonry work. The mix of personalities has a higher variation across the masons and it has been found across managers that teams may fail because they are unsuitable in terms of personality (Varvel et al, 2004). Thus, it is of interest to establish (in isolation) whether personality factors have an effect on productivity. The mix of skills and capabilities in this study will be assumed similar across the crews.

\section{[Insert Fig. 2 here]}

\section{Model components}

Personality factors 
The term personality is often referred to as a psychological construct (Maltby et al, 2017) and the characteristics and qualities typical of an individual (Chamorro-Premuzic, 2015). Personality is used to describe behavioural regularities and the underlying structures, dynamics, processes, and tendencies of an individual (Hogan and Holland, 2003). Some researchers contend that while individuals may behave differently in different situations, personality characteristics tend to be universal (McCrae and Costa, 1997), regular (Boyle et al, 2008), stable (Maltby et al, 2017), proximal to behaviour (Gosling et al, 2003), and visible in other's behaviour, making them enduring characteristics of individuals (Gregory, 2015).

The five-factor model of personality (McCrae and Costa, 1987; Goldberg, 1990) is a hierarchical organization of personality characteristics in terms of five basic dimensions (OCEAN). These dimensions developed into the fundamental five factors of personality in the 1980's after multiple researchers from different traditions using self-reports, ratings, and theoretically based questionnaires in diverse groups and samples found convergent and discriminant validity across instruments (John, 1990). Today, the five-factor model is a widely accepted theory among psychologists (Gosling et al, 2003). It is recognized as an adequate tool for assessing individual personality and identifying the most important ways in which individuals (across cultures and groups) differ in their emotional and attitudinal styles (McCrae and John, 1990; Ones et al, 2017). Personality dimensions are unlikely to experience ordinal changes (Hofman and Jones, 2005) and are consistent and steady over time (Barrick and Mount, 1991). Since the five dimensions exhaust the full range of personality characteristics and are comprehensive, every person's personality can be described in terms of these five dimensions (Goldberg, 1990), giving a basis for exploration of the relation between personality and other phenomena (McCrae and John, 1992).

Personality dimensions are used to understand relationships and interactions between individuals, as these are a function of the personal characteristics of individuals (Kelly and Conley, 1987). Personality dimensions have also been used for describing and predicting attitudes (Ones et al, 2007), behaviors (Shuck and Reio, 2013), fit (Campion et al, 1993; Halfill et al, 2005), outcomes (Hogan and Holland, 2003), and performance (Cohen and Bailey, 1997) in many organisational settings. The five dimensions have been investigated in meta-analytic studies and have been used in applied psychology (Chamorro-Premuzic, 2015), organisational psychology (Peeters et al, 2006) and human resource management (Campion et al, 1993) to determine the relationship between personality and multiple job outcomes (Cohen and Bailey, 1997; Hogan and Holland, 2003; Barrick and Mount, 1991; Goldberg, 1990). Results of these studies have shown that organizations use personality factors for recruitment and for personnel selection, but also to support decision making when staffing projects and forming teams of workers (Kristof-Brown and Stevens, 2001).

The five-factor model has the following dimensions of personality with behavioral regularities: i) Openness: creative, imaginative; ii) Conscientiousness: efficient, organized; iii) Extraversion: assertive, talkative; iv) Agreeableness: appreciative, 
cooperative; and v) Neuroticism: anxious, emotional. To determine personality, a revised questionnaire of the big five (John et al, 1991) was administered in-person to the masons. The big-five inventory (BFI) used a 44-item of short phrases based on typical trait adjectives to which contextual or clarifying information is added. The BFI has shown increased reliability over shorter instruments such as the ten-item (TIPI) or five-item (FIPI) personality measures. Furthermore, confirmatory factor analysis has found the BFI to have the highest validity of all instruments (John and Srivastava, 1999). The BFI presented 44 items to determine their personality profile and twenty-eight masons completed it individually (see Appendix A). Masons were instructed to consider their range of behaviour and, for each characteristic, provide three responses based on the extent to which the statement applied using least (L), usual (U), and most (M) to make the acronym LUM. By using LUM, masons could consider their range of behaviour to mitigate the effects of mood (Chamorro-Premuzic, 2015). The masons had to mark a score on a 7-point response format from (1=strongly disagree) to (7=extremely agree) to indicate the extent to which they agreed or disagreed with the statements as they related to them (see Appendix A). Missing items were treated by using the response to the closest synonym item as recommended by John and Srivastava (1999). LUM scores for each question were aggregated and the mean score was calculated for each response. Response scores were then used to calculate the overall score in each of the five dimensions of personality. For instance, mason 1 responded to "is talkative" $L=4, U=5, M=6$ hence the score for this question is the average of the responses which is 5 . This procedure was followed for the 44 items and for all the masons.

\section{Compatibility}

When grouping individuals, their personality characteristics are combined and how well they match can be measured by compatibility. In this study, compatibility is defined as a measure of the capability of a group to interact and work well together to achieve good performance (Tett and Murphy, 2002; Garrison, 1970). If the personality differences of the individuals in a team are not excessive or incompatible, their interactions create a favorable environment that facilitates their communication and coordination resulting in higher performance. There are two theories concerning compatibility: dissimilarity and similarity in personality. In the case of dissimilarity, theories suggest that a mix of different personalities is necessary to produce a creative atmosphere in which members have opportunities to learn (Kichuk and Wiesner 1997). Dissimilarity has been shown to produce positive results for tasks high in creativity or with greater cognitive demands (Peeters et al, 2006). Dissimilar workers bring different ideas and perspectives to the work environment and are more willing to experiment new things (Mohammed and Angell, 2003). Having a dissimilar range of personalities within the group also encourages members to experiment (Molleman et al, 2004). However, it was found that groups with dissimilar personalities spend more time taking decisions (Witte and Davis, 1996), experienced more conflicts and were less productive (Kichuk and Wiesner, 1997; Neuman et al, 1999). 
Theories related to similarity (Festinger, 1954; Van Vianen and De Dreu, 2001) suggest that people have a fundamental need for consensual validation of their perspectives, which can be met by interacting with similar others. Individuals that share similar characteristics tend to have similar ways to work and work well together to complete their tasks (Kristof-Brown and Stevens, 2001). Similar workers are also more willing to communicate, share information, and resolve conflicts effectively (Witte and Davis, 1996). Sharing personality characteristics helps workers meet their individual needs (Reagans et al, 2004) due to mutual attraction evoked by commonalities (Bowers et al, 2000) and people are often more motivated to work in environments similar to their personalities (Furnham et al, 2005). Thus, workers will be most successful in groups that share their personalities, and this often results in increased group performance (Dineen et al, 2002).

Based on these expectations and results, in this paper, compatibility is measured as a tendency of a crew to share similar personality characteristics. To calculate similarity, the average of the dimensions of personality was taken based on the method of operationalizing personalities for different team compositions presented in Barrick and Stewart (1998) and Neuman et al, (1999). This method determines that team composition is operationalized depending on the type of task and suggests a taxonomy to analyze the results of personality composition. For additive tasks, which require the summing of resources/efforts for performance, the mean level of the personality factors is the most appropriate operationalizing method since additive tasks are structured so that the contribution of each worker adds to the group helping the team to succeed. Since masonry processes consist of additive tasks and are interdependent tasks in which the inputs of each team member combine for a collective output, we decided to operationalize the team composition by taking the average of the different personality dimensions.

A number of assumptions were made when determining the compatibility of the crews. The purpose of these assumptions is to simplify the process of proposing a metric to measure compatibility of personality among workers. The assumptions are as follows: 1) A crew of workers that is compatible, interacts and work well together to achieve its tasks; 2) The higher the compatibility, the higher their performance; 3) Compatibility is calculated through explicit comparisons of the OCEAN (Peeters et al, 2006); 4) Compatibility is an aggregated mean of the individual personality scores in OCEAN for each of the masons in the crew (Neuman et al, 1999); 5) The coefficients of the personality dimensions are assumed equal because without any further information it is naturally to propose that all the dimensions influence compatibility equally.

Compatibility was calculated using the principle of similarity theory, that is, workers with similar personalities are more compatible (Tziner, 1985; Kristof-Brown et al, 2005). To diminish subjectivity, explicit comparisons were used to measure similarity and calculate compatibility. Similarity was assessed by calculating distances in a multidimensional space matrix for each crew (McCune and Grace, 2002), where a smaller distance reflects a higher similarity (higher compatibility) and a greater distance a higher dissimilarity (lower compatibility). The compatibility matrix in the case of two masons is a two by five matrix 
$\left(p_{i j}\right)_{i=1,2 ; j=1,2, \ldots, 5}$, where $p_{i j}$ is the personality factor $j$ of mason $i$, and the personality factors are ordered in the following way: openness $(j=1)$, conscientiousness $(j=2)$, extroversion $(j=3)$, agreeableness $(j=4)$ and neuroticism $(j=5)$. For instance, $p_{12}$ corresponds to the personality factor 2 (which is Conscientiousness) of mason 1. Landau and Everitt (2004) state that the most commonly used measure of distance is the Euclidean, which represents the distance between two scores across a range of variables or any two vectors taken across the same variables. The raw Euclidean distance is given by equation (1):

$$
d=\sqrt{\sum_{j=1}^{5}\left(p_{1 j}-p_{2 j}\right)^{2}}
$$

In Equation (1): $d$ is the raw Euclidean distance for two scores each measured on five variables $p_{1 j}, p_{2 j} ; j=1, \ldots, 5$. Computing $\mathrm{d}$ for crew 1, composed by mason 1 and mason 2, (see Table 1), $d=2.603$. To make this definition dimension invariant (which is just a matter of taste), the raw Euclidean distance is divided by $\sqrt{v}$ where $v=$ the number of variables (Barrett, 2005), which in this case is five. To reflect the operations above, the Scaled Euclidean distance is given by (2):

$$
e=\frac{\sqrt{\sum_{j=1}^{5}\left(p_{1 j}-p_{2 j}\right)^{2}}}{\sqrt{v}}
$$

In the case of crew $1, e=0.8163$. Note that equation (3) calculates the distance between scores as dissimilarity using the formula adapted from Armstrong (2018). However, Scaled Euclidean distance can also be used to represent similarity (McCune and Grace, 2002). Thus, the distance between the worker's personality dimensions was converted to a similarity value (Segaran, 2007) using (3):

$$
s=\frac{1}{1+e}
$$

In equation (3): $s=$ similarity between scores; $e=$ Scaled Euclidean distance (dissimilarity). The resultant scores were used to populate a distance matrix showing the similarity between each pair of masons where, 0 represents maximum dissimilarity and 1 represents absolute similarity. In the case of crew $1, s=0.55$. To calculate compatibility, each personality dimension is an aggregate of the mean of its variables. This approach ensures equal weighting and ensures that the difference between the number of questions in each factor does not affect the mean score in that factor. The next step was measuring the productivity of the crews. 


\section{Productivity}

Productivity is widely used in construction to measure performance. In general, productivity is defined as the ratio between the output of a production process over its inputs. Inputs include resources such as labor, time, equipment, materials, and energy. Outputs include the number of goods produced to a defined quality and standard (Loosemore, 2014). There are two categories

to define productivity: single-factor productivity or multi-factor productivity (Crawford and Vogl, 2006). Single factor considers one input (e.g labor) and multi-factor considers two or multiple factors (e.g. labor, equipment, materials). Additionally, productivity is measurable at several levels (Kenley, 2014); from macroeconomic measures at the industry level which combine projects (Nasir et al, 2014) to microeconomic measures at the project level which combines activities and at the activity or task level (Meikle and Best, 2015).

There are multiple techniques and methodologies to measure productivity such as the construction industry institute method (CII, 1990), the XYZ model (Chitester, 1992) along with activity sampling techniques (Thomas, 1991), and time studies (Salvendy, 2001). In addition, detailed methods to measure productivity at the industry level (Thomas et al, 1990; Arditi and Mochtar, 2000), project level (Shehata and El-Gohary, 2011), and task level (Ailabouni et al, 2007; Thomas and Sudhakumar, 2013b) have been developed. Consequently, the selection of how to define and measure productivity generally depends on two factors, which include the scope of the measure and the availability of data (Gatti et al, 2014). Among the proposed productivity measurement methods and considering the scope of this study, single-factor productivity was measured using the task-level model (4) adapted from Shehata and El-Gohary (2011):

$$
\text { productivity }=\frac{\text { unit of work }}{\text { work hours }}
$$

This model is widely used in labor-intensive operations such as masonry (Dozzi and AbouRizk, 1993) and focuses on the actual work being performed at the crew and task levels. The unit of work is the summation of weekly quantities completed per crew and in this case, it was measured in total area $\left(\mathrm{m}^{2}\right)$ of composite cavity wall construction. Composite cavity wall comprises of $102.5 \mathrm{~mm}$ facing brick, $150 \mathrm{~mm}$ cavity, $100 \mathrm{~mm}$ blockwork, and includes all ancillaries such as insulation, wall ties, lintels, cavity trays, and damp-proof courses. Composite cavity wall is the most commonly output of masonry construction used by UK house builders (Brockman et al, 2010). Work hours were measured as productive time, that is, the summation of work hours minus unavoidable delays such as weather and meal breaks. Productivity was measured across a period of 16 consecutive weeks and the Thomas and Zavrski (1999) baseline methodology was used as a framework to select the seven most productive weeks and determine the mean productivity of each two-mason crew. The reader is referred to Thomas and Zavrski (1999) for further details on the baseline methodology. 


\section{Calculating compatibility and measuring productivity}

\section{Setting}

The study was conducted in eight masonry projects located in the county of Tyne and Wear in the North East of England. Data collection was taken simultaneously during the same time period to ensure that projects had similar temperature and weather conditions. To account for any variability across projects (due to weather, material availability, job difficulty, and other factors that may have impacted the productivity results), data was taken across 16 consecutive weeks and the seven most productive weeks were used (see above). All the projects were private housing developments with similar physical settings and complexity of work. This ensured identical workflows and measurement validity and served as a control variable for the work setting as only house building projects were considered. Projects had two-mason crews and crews were formal teams. Additionally, crews viewed themselves and were seen by others as teams, that is, crews interacted and shared resources to accomplish mutual tasks (Sundstrom et al, 1990). The two-mason crew size did not change because workload was stable in all the projects during the data collection process. Therefore, crews were comparable and there was no need to standardize productivity. Each crew performed the same tasks (laying masonry units and installing rebar and wire for reinforcement and ancillaries). In addition to shared resources and tasks, work was often sequentially interdependent in that masons depended on each other for completing the tasks. Thus, the crews were teams and were similar in the way they were managed by one foreman on-site, who coordinated work. Masons were qualified bricklayers (not apprentices) so had previously worked in masonry projects (at least 5 years' experience) to control for experience.

\section{Sample}

The sample for this study was drawn from self-employed and subcontracted bricklayers currently working for house builders in the UK construction industry. The sampling approach was that of purposive non-random sampling (Hesse-Biber and Leavy, 2006). Purposive to guarantee the participants in the sample were knowledgeable with masonry construction and had experienced similar work responsibilities of laying masonry units and working in crews. In addition, a convenience (nonrandom) sample was used due to a long-standing relationship with a general contractor and readily available access to the supply chain via the co-author's employer. Subcontracted masons were chosen, as they were available within the selected projects. Twenty-eight masons grouped in 20 crews participated in the study and data was collected from August 2017 to March 2018. The minimum age of masons was 18 years of age, $25 \%$ had age between 25 to 30 years, $17.86 \%$ between 31 to 25 years and $17.86 \%$ between 46 to 50 years. The mean age was 36.12 years and all the masons were males. The experience in masonry 
construction ranged from five to 47 years with a mean of 23.3 years $(\mathrm{SD}=13.08)$. The BFI (Appendix $\mathrm{A})$, adapted from John and Srivastava (1999), was administered to each mason. All twenty-eight masons completed the questionnaire early during the data collection process. Note that each mason completed the questionnaire one time, since personality tends to be regular (Boyle et al, 2008), stable (Maltby et al, 2017). In other words, it was assumed that the personality of the masons did not change over time and that it will not impact the productivity differently during the 16 weeks.

\section{Results}

The questionnaire responses produced individual personality profiles for OCEAN and using the coefficients from the standardised Euclidean Scalded distance matrix, equations (1) to 34), the compatibility profile for each masonry crew was calculated as shown in Table 1.

\section{[Insert Table 1 here]}

Note that the compatibility coefficient ranged between 0.36 to $0.78(M=0.53, S D=0.12)$ among the crews. Low compatibility between masons commonly occurred when neuroticism was significantly elevated in one mason. The two masons with the highest levels of neuroticism were masons $\mathrm{m} 4$ and $\mathrm{m} 23$. Interestingly, there was very little variation among other traits for these participants. The two masons displaying the lowest levels of extraversion also displayed very low levels of compatibility among the sample as shown in Table 1. Productivity data are presented in Table 2 for the seven most productive weeks as selected using the baseline productivity method (Thomas and Zavrski, 1999). The productivity of the 20 crews was measured on a weekly basis across the eight separate housing developments, totalling 273 measured hours per crew. Cumulative output across the crews ranged between $209 \mathrm{~m}^{2}$ to $356 \mathrm{~m}^{2}$ and productivity ranged between $0.887 \mathrm{~m}^{2}$ to $1.494 \mathrm{~m}^{2}(M=1.189, S D=$ 0.174) per hour (see Table 2).

\section{[Insert Table 2 here]}

To index the variability in productivity, the standard deviation or the variance in productivity over the seven weeks was used. Inspection of the two distributions revealed that the standard deviation was more normally distributed and has been used in other studies (Hofmann and Jones, 2005; Schneider et al, 2002). The internal reliability of the big-five questionnaire was examined to ensure internal consistency of the study. The Cronbach's alpha was used to measure internal reliability and interitem correlation for the five factors. In interpreting the alpha statistic, a factor's measure was said to be moderately consistent if the alpha was between 0.50 to 0.70 and highly reliable if it was approximately 0.7 or greater for that factor (Farrell et al, 2017). All data analysis was performed using IBM SPSS version 18.0. 
The questionnaire displayed high reliability across all factors, except for neuroticism that resulted in a slightly lower value (see Table 3). Cronbach's alpha coefficients ranged from 0.64 for neuroticism to 0.85 for extraversion. The mean alpha coefficient across all factors was 0.70. Standardised alpha coefficients based on inter-item correlations, displayed similar ranges. However, the mean reliability was marginally higher at 0.71 . These results show that the questionnaire had consistent

and acceptable alpha reliabilities across all factors. Despite the small sample size, mean alpha reliability $(\alpha=0.70)$ is comparable with other instruments such as the FIPI $(\alpha=0.68)$, and TIPI $(\alpha=0.72)$. Further analysis showed that alpha coefficients could improve from 0.68 to 0.72 for openness when the trait adjective "Prefers work that is routine" is omitted. Similarly, removing the trait adjective "Moody" from the questionnaire improves internal reliability significantly for neuroticism from 0.64 to 0.69 (see Appendix A).

\section{[Insert Table 3 here]}

\section{Relationship between Personal Compatibility and Crew Productivity}

The data were examined to determine whether the dataset was parametric or non-parametric to select the appropriate analysis test. Farrell et al (2017) state that data are parametric when they fall within certain boundaries or parameters. Bryman and Cramer (2005) outline three boundaries for parametric data: 1) the level of measurement must be of interval or ratio scaling; 2) the distribution of the population scores must be normal; 3) the standard deviation of both variables are equal or homogenous. Accordingly, both the compatibility and productivity scores were categorised as ratio data as the scales were at equal intervals, continuous, and both had a genuine zero meaning no compatibility or productivity (Hinton et al, 2014). To satisfy boundaries two and three, the data were tested for normality using the Kolmogorov-Smirnov and Shapiro-Wilk tests. To determine whether greater compatibility of personality between the masons in a crew leads to higher productivity, a hypothesis was established:

$$
\begin{aligned}
& H_{o} \text { : Greater compatibility in the crew does not increase productivity } \\
& H_{1} \text { : Greater compatibility in the crew leads to higher productivity }
\end{aligned}
$$

Prior to testing the null hypothesis, the compatibility data were first tested for normality using the Kolmogorov-Smirnov and Shapiro-Wilk tests. The results showed that the compatibility data are normally distributed using both the KolmogorovSmirnov (stat. 0.129, $p=0.200$ ) and Shapiro-Wilk tests (stat. 0.947, $p=0.327$ ). Hinton et al (2014) state that $p<0.05$ indicates that the sample distribution is significantly different from the normal distribution. Consequently, normality of the data set was assumed.

A correlation analysis was performed to assess the relationship between compatibility and crew productivity. Pearson and Spearman are the most common techniques for correlation analysis (Bryman and Cramer, 2005) and are used to assess the 
relationship between independent variables (e.g. compatibility) and dependent variables (e.g. crew productivity). Pearson's correlation assesses linear relationships between variables and assumes homoscedasticity, data are normally distributed, and data are interval or ratio. Spearman's correlation assesses monotonic relationships whether they are linear or not and can be used when one of the assumptions in Pearson is not satisfied. Since the relationship might not be linear and the scores are not evenly distributed among the line of regression, Spearman's was used (Hinton et al, 2004). This analysis utilises the same calculations as Pearson's, however, performs monotonic relationships (whether linear or not) and correlations based on rank. The Spearman's rho coefficient $\left(r_{s}\right)$ determines two characteristics of the relationship: the direction of the relationship and the strength of the relationship. The direction between two variables can be positive or negative. A positive relation represents two variables that change in the same direction (i.e. increasing or decreasing simultaneously), and a negative relationship represents two variables that change in opposite directions (i.e. if one variable increases the other will decrease). The magnitude of the relationship is represented by the correlation coefficient and varies between -1 (negative) and 1 (positive) correlations (Bryman and Cramer, 2005). Based on the value of the coefficient, the relationship can be classified into four categories: $r_{s}<0.1$, no correlation; $0.1 \leq r_{s} \leq 0.3$, weak correlation; $0.3 \leq r_{s} \leq 0.5$, moderate correlation; $r_{s} \geq 0.5$, strong correlation (Hinton et al, 2014). As the hypothesis is one-tailed, the significance level was set at $p \leq 0.01$, which reduces the chance of type error I (Farrell et al, 2017).

Table 4 presents Spearman's coefficient correlations between the big five factors. To balance Type I and II errors, both the $p<0.05$ and $p<0.10$ significance levels were reported (Campion et al, 1993). Note that neuroticism was negatively correlated with all traits. Low compatibility between masons commonly occurred when neuroticism was significantly elevated in one worker. These findings are consistent with previous studies in non-construction domains, most notably Kichuk and Wiesner (1997) and Peeters et al. (2006). The strongest negative correlation was between neuroticism and conscientiousness $\left(r_{s}=-0.686\right)$. The most significant positive correlations were observed between agreeableness and conscientiousness $\left(r_{s}=\right.$ $0.575)$ followed by openness and conscientiousness $\left(r_{s}=0.507\right)$. Openness and agreeableness displayed a moderate positive correlation $\left(r_{s}=0.340\right)$ at the $p<0.05$ significance level. No significant correlations were observed between extraversion and agreeableness or extraversion and openness.

\section{[Insert Table 4 here]}

To determine whether greater compatibility within masonry crews leads to higher productivity, the null hypothesis was tested using a one-tailed test. The Spearman correlation analysis was performed, and it shows a positive correlation between compatibility and productivity $\left(r_{s}=0.758\right)$ which can be observed in Table 5 . The results also include the means, standard 
deviations, and intercorrelation between the variables. The means and standard deviations for personality were calculated based on the collected responses to the questionnaire. For each pair of variables, the significance of the relationship between the two variables was tested and the $p$-values were reported. Bryman and Cramer (2005) suggest that a Spearman correlation coefficient ranging between 0.51 to 0.70 represents a good relationship and a coefficient ranging between 0.70 to 0.89 represents a high correlation. Therefore, as $p<0.01$ the null hypothesis was rejected, that is, the data supports the possibility of a positive correlation between compatibility and productivity (in the analysis below it is shown that the data even supports that this correlation is at least moderate).

\section{[Insert Table 5 here]}

\section{Confidence intervals}

It is important to account for the uncertainty of the estimation provided by the data for the correlation between compatibility and productivity. This is done by finding confidence intervals for the true correlation between compatibility and productivity centred at the value estimated from the data. The procedure is described below. First, the pair of variables (compatibility, productivity) were tested to be normally distributed, that is, it was checked if it can be assumed that this pair of variables forms a bivariate vector normally distributed. According to Mardias test (skewness $p$-value: 0.74961 , kurtosis $p$-value: 0.50624 ), Henze-Zirkler test ( $p$-value: 0.64489) and Royston test ( $p$-value: 0.60577$)$, the hypothesis of bivariate normality cannot be rejected, so it is assumed bivariate normality from now on.

Assuming (bivariate) normality of the data, and as is usual when finding a confidence interval for the linear correlation coefficient, the Fisher transform is used, which is given by (5):

$$
u_{r}=\operatorname{arctanh} r=\frac{1}{2} \ln \left(\frac{1+r}{1-r}\right)
$$

It is well known (see Vrbik, 2005) that $u_{r}$ is normally distributed with mean (the letter $\rho$ below represents the true correlation in the population, so $r$ is an estimator of $\rho$ ) (see (6)):

$$
u_{\rho}=\operatorname{arctanh} \rho
$$

and approximate variance (7):

$$
\sigma^{2}=\frac{1}{N-3}
$$

where, $N$ is the sample size, in this case $\mathrm{N}=20$. From this it can be deduced that the random variable $\left(u_{r}-u_{\rho}\right) / \sigma$ is (approximately) normally distributed with mean zero and variance 1 . Hence, to get a confidence interval of $95 \%$ for $u_{\rho}$, the interval is: 


$$
-1.96 \leq \frac{u_{r}-u_{\rho}}{\sigma} \leq 1.96
$$

which leads to the following inequality

$$
u_{r}-1.96 \sigma \leq u_{\rho} \leq u_{r}+1.96 \sigma
$$

In the case given by the sample in this study, $r=0.724$ and $N=20$. This gives $u_{r}=\operatorname{arctanh} 0.724=0.916001$ and $\sigma^{2}=1 / 17=$ 0.2426

$$
0.4406 \leq u_{\rho} \leq 1.3913
$$

which corresponds, by inverting the formula for the Fisher transform (that is by taking tanh, which is an increasing function, on each term of the inequality) to an interval of $95 \%$ confidence for the true correlation $\rho$ given by:

$$
0.4141 \leq \rho \leq 0.8834
$$

Note that if the true correlation between compatibility and productivity falls within this interval, then this correlation would be at least moderate (that is, larger than 0.3). This is in accordance to the categories for correlation in (Hinton et al (2014).

\section{Bayesian inference}

A bit of Bayesian statistics might give a better idea of what the data obtained in this experiment is telling. Among the advantages of using this approach in contrast with the frequentist approach (the one used above, and whose main outcome is just a $p$-value), is that the Bayesian approach is founded into a firmer theoretical ground (Jaynes, 2003) and that it gives the possibility of computing how much more likely is a hypothesis compared to another given the collected data. The weak point of this approach is that an a priori probability distribution has to be established, but in this case, as the purpose is to find whether there is a positive correlation between compatibility and productivity, the a priori distribution will have to reflect the fact that there is no bias with respect to what to expect on how correlated the variables compatibility and productivity are.

Let's denote by $H_{\rho}$ the statement "the correlation between compatibility and productivity is exactly $\rho$ ". Given any set of data of size $N$, let $r$ be the correlation coefficient obtained in an experiment with this data set. Assuming bivariate normality of the pair (compatibility,productivity), (Vrbik, 2005), then the random variable $u_{r}=$ arctanh $r$ is approximately normally distributed with mean $u_{\rho}$, where $\rho$ is the true correlation between the two variables, and variance $\sigma^{2}=1 /(N-3)=1 / 17$. That is $u_{r}$ has the following probability density function under the assumption that the true correlation between compatibility and productivity is $\rho$ :

$$
p\left(u_{r} \mid H_{\rho}\right)=\frac{1}{\sqrt{2 \pi} \sigma} e^{-\frac{\left(u_{r}-u_{\rho}\right)^{2}}{2 \sigma^{2}}}, \quad \text { where } \quad u_{x}=\operatorname{arctanh} x, \quad \sigma^{2}=0.2426
$$


Next, let's compute the probability of $H_{\rho}$ given the data obtained in the experiment. In this case, as no bias was assumed, and that the correlation coefficient could be any number between -1 and 1 , the expression of this belief is that $\rho$ is distributed uniformly on the interval $[-1,1]$, so the prior distribution for the correlation coefficient $\rho$ that it is denoted by $\mathrm{f}(\rho)$ is equal to $1 / 2$ if $\rho$ belongs to the interval $[-1,1]$ and 0 otherwise. Using Bayes theorem, the probability density wanted is then given by:

$$
p\left(H_{\rho} \mid u_{r}\right)=\frac{p\left(u_{r} \mid H_{\rho}\right) f(\rho)}{\int_{-1}^{1} p\left(u_{r} \mid H_{\rho}\right) f(\rho) d \rho}
$$

and, using all the information above, the following probability distribution function for $H_{\rho}$ (i.e., for the true correlation coefficient) is obtained, given that from the data we have $u_{r}=0.6267$ :

$$
p\left(H_{\rho} \mid u_{r}=0.6267\right)=\frac{1}{0.98835} e^{-\frac{\left(u_{\rho}-0.6267\right)^{2}}{0.4852}} .
$$

Therefore, the probability that the correlation is larger than 0.3 (that is, the correlation is at least moderate) is:

$$
\int_{0.3}^{1} p\left(H_{\rho} \mid u_{r}=0.6267(r=0.724)\right) d \rho=0.674672
$$

Hence, according to the data, it is led to believe that having a correlation of 0.3 (a moderate correlation) is twice as likely as having a correlation lower than 0.3 (a weak correlation). Another simple calculation also shows that the data supports the fact that having a correlation larger than 0.45 is a more likely than having a correlation less than 0.45 . Finally, the expected value obtained for the correlation, given the data, is:

$$
\int_{-1}^{1} \rho \cdot p\left(H_{\rho} \mid u_{r}=0.6267(r=0.724)\right) d \rho=0.4397
$$

which is clearly a moderate correlation. As an observation, under the bias of positive correlation (belief that compatibility and productivity are positively correlated), repeating the previous calculations the result is that having a moderate correlation (correlation greater than 0.3 , probability: 0.728 ) is almost three times more likely than having a weak correlation (correlation smaller than 0.3 , probability: 0.272 ). Note that all this numerology points to the fact that compatibility and productivity are in a worst case scenario at least moderately correlated, and that the results presented in this paper deserve to be replicated.

\section{Discussion and Conclusions}

The construction industry has been characterised by having low labor productivity. Labor factors such as the interrelationships between the workers in a crew have been found to affect productivity. Workers have many distinct personality characteristics and when working in crews the mix or combination of personality influences crew performance. It is expected that workers 
that have compatible personalities will be more productive. However, the actual relationship between compatibility and productivity has not been tested and assessed in construction. Therefore, it is theoretically and practically relevant to study the relationship between compatibility of personality and productivity and in real live construction projects.

Based on an extensive literature review, a theoretical model was established to reflect the influence of compatibility of personality and productivity. A hypothesis was developed to investigate the potential relationship between compatibility of personality and productivity at the task level. To test the hypothesis and validate the theoretical model, empirical data was gathered from eight construction projects. From the projects, productivity and personality data was gathered. An adapted questionnaire of the big-five was used to determine individual personality profiles of a group of twenty-eight masons. Personality profiles were used to calculate a compatibility metric between the masons in the 20 participating crews. The compatibility metric proposed was determined using the Euclidean distance as a measure of similarity of personality. Compatibility was selected as predictor of productivity. Productivity was measured at the task level. Correlation analysis was performed to investigate the relationship between compatibility and productivity.

Initial results showed that the personality questionnaire had consistent and acceptable reliability across all factors, reliability scores greater than 0.71 , except for neuroticism which had a lower score of 0.64 . Further analysis showed that among the personality characteristics, conscientiousness and agreeableness had the strongest relationship with productivity. For conscientiousness, this finding is in line with findings on the relationship between conscientiousness and team performance in psychology studies (Barrick et al., 1998; Neuman et al., 1999). Note that one key aspect of people high in conscientiousness is that they plan or systematically work towards goal completion. In teams in which there is a fairly long period of time to complete tasks and there are high levels of interdependence (such as in masonry crews), conscientiousness was had a positive effect on the productivity of the crew. For agreeableness, this finding is in line with a number of similar studies on the relationship between agreeableness and team performance (Barrick et al., 1998; Van Vianen and De Dreu, 2001). Perhaps the effect of agreeableness on team performance is affirmed through interpersonal facilitation within the team, as pointed out by Peeters et al., (2006). From the results of this study, crews whose masons scored both highly (greater than 5.52) on conscientiousness were the crews with the highest productivity. For agreeableness, the most productive crews were the ones whose masons scored highly (greater than 5.37) and similarly (difference between agreeableness score of less than 0.44).

Significant correlations were observed between agreeableness and conscientiousness, openness and conscientiousness, and extraversion and conscientiousness. The most significant finding was that neuroticism negatively correlated with each of the remaining personality factors $\left(\mathrm{O}, r_{s}=-0.360\right)\left(\mathrm{C}, r_{s}=-0.686\right),\left(\mathrm{E}, r_{s}=-0.4386\right),\left(\mathrm{A}, r_{s}=-0.373\right)$. Additionally, as evidenced in the data, low compatibility between masons commonly occurred when neuroticism was significantly elevated in 
one mason. Similar findings were found in psychology studies by Kichuk and Wiesner (1997), Peeters et al (2006), and Reilly et al (2002). From this it can be concluded that neurotic crew members can have an adverse effect on team effectiveness by disrupting the cooperation. Therefore, elevated neuroticism is expected to be negatively related to team performance.

Further analysis showed that compatibility has a moderate positive relationship with crew productivity at the task level. It was found that more than half of the variability in crew productivity is accounted for by compatibility. The correlation coefficient was 0.724 . This result is significant, as it shows that personality characteristics influence productivity and need to be accounted by foremen and managers when forming and managing masonry crews. In other words, the findings of this study suggest that foremen should form crews of workers that have similar personalities as it has been found that it increases crew productivity at the task level. After determining the correlation coefficient between compatibility of personality and productivity, a series of statistical analyses were performed to evaluate if the coefficient represents the true coefficient (of the population) and its expected value.

A confidence interval analysis showed that with a confidence of $95 \%$ around $r=0.724$, it should be expected to find the value of the true correlation coefficient between $0.4141 \leq r \leq 0.8834$. Note that if the true correlation between compatibility and productivity falls within this interval, then this correlation would be at least moderate (that is, larger than 0.3). Bayesian inference shows that according to the data, it is led to believe that having a correlation of 0.3 (a moderate correlation) is $67 \%$ more probable than having a correlation lower than 0.3 (a weak correlation). Another simple calculation showed that the data supports the fact that having a correlation larger than 0.45 is more likely than having a correlation less than 0.45 . Finally, the expected value obtained for the correlation, given the data was 0.4397 . All this numerology pointed to the fact that compatibility and productivity are in a worst case scenario at least moderately correlated.

The integration of the results obtained hold important information about the relationship between compatibility and personality. The data supports the possibility of a positive correlation between compatibility and productivity and further it even supports that this correlation is at least moderate. This result is relevant for project managers and foremen as it indicates that the personality of the workers should be considered as a factor when forming productive crews, that is, personality has an effect on crew productivity. In this particular case, crew productivity can be increased by forming crews of workers with similar personalities. The substantial main effects of the elevation of conscientiousness and agreeableness, and the absence of such effects for other personality characteristics have important implications for crew composition in practice. This will help construction companies, contractors, and subcontractors to structure jobs in terms of teams. Preferably, crews should be composed of workers that are highly agreeable and conscientious. This means that in the selection process of future crews, 
workers' personality should be considered as one of the selection criteria. Personality offers unique potential for understanding and improving fit within work teams and for better predicting productivity.

\section{Research limitations}

Several limitations may affect the significance of the research study presented. First, workers accomplished only masonry tasks. Hence the obtained compatibility-crew productivity relationship may not be applicable to other labor-intensive construction activities. Second, the number of workers was limited, as only two-mason crews participated in the study and the projects were all located in the North East of England. Thus, the sample size may be small to drive more general conclusions about the relationship between compatibility and productivity. In terms of location, although projects were located in the same region within the UK, weather and temperature conditions may differ in other geographical locations and this may have an effect on productivity. Third, we used means as the operationalization for the personality factors. Barry and Stewart (1997) used proportions and Mohammed and Angell (2003) used standard deviation scores. This may have had an influence on the results of the sample and results may alter when analyses are conducted with larger samples. Fourth, we did not consider moderating effects that might influence the results. These moderators should be tested independently. For instance, there might be effects related to the period of time crews cooperate and how their tasks are interdependent. Another effect was that that the masons completed a paper-based questionnaire, which could have introduced some biased as it was given face to face. The more productive crews had a high average score on agreeableness and conscientious. However, careful consideration should be given to whether this is the due to a mason having a very high score on those factors within a crew. Finally, other human-related factors that affect productivity were not considered. Although the research outcomes do not identify all the features of a crew that affect their productivity, the outcomes contribute to the progression of knowledge about personality and how it influences productivity.

\section{Future research}

The discussion of the results allowed several important directions for future research. A random allocation of masons to crews and private assessment of their personality (which will not be known even to the researchers) could be done in order to simulate the standard double-blind experiments used in medical research. This will allow to compare whether the time that a crew has worked together influences their productivity as well as to avoid bias in distributing a questionnaire face to face. Additionally, experiments on site with a similar methodology can be conducted with crews from different trades and sizes to determine whether the positive relationship between compatibility and productivity still holds. Third, other human-related factors in a 
crew (e.g. skills, capabilities, qualifications, cohesion, and motivation) that affect productivity could be studied alongside personality to determine a more comprehensive crew productivity function. This productivity function could be used by managers, contractors, and subcontractors to predict productivity and support the planning and construction phases of projects, key aspects in the field of labor management.

To predict crew productivity, additional experiments are highly desirable to determine the shape of the productivity function. The shape of this function is of interest because it may have implications over the selection of the workers in a crew. For instance, based on the findings of this study, compatibility is one aspect that affects productivity. If future experiments confirm this, then it can be stated that compatibility can be used to predict crew productivity. Consequently, the question that must be raised now is the following: is the shape of the productivity function universal? (Florez and Cortissoz, 2016). By universal it is meant that, aside from its exact values, it does not depend on the construction activity or the trade, and it will be consistent. For the particular case of compatibility (and assuming is one factor while controlling other factors), two workers that have the same compatibility would be expected to have a similar productivity in a task every time they are grouped in a crew. If this universality is found, it would be an outstanding discovery. The reader is asked to think about the utility function in economics, whose shape (concave) is universal, and it is determined from basic economic principles. Hopefully firm theoretical grounds can be found based on the knowledge contributed by this study to predict the shape of the crew productivity function.

\section{Data availability}

Some or all data, models, or code generated or used during the study are proprietary or confidential in nature and may only be provided with restrictions.

\section{Acknowledgments}

The authors would like to thank the two main contractors and masonry subcontractors in the UK for participating and collaborating in this study. Any errors or omissions are solely the responsibility of the authors.

\section{References}

Ailabouni, N., Gidado, K. and Painting, N. (2007). Factors affecting employee productivity in the UAE construction industry. Conf. for Postgraduate Researchers of the Built Environment (PRoBE), 33-46.

Arditi, D. and Mochtar, K. (2000). Trends in productivity improvement in the US construction industry. Constr. Manage. Econ. 18(1), 15-27. 
Armstrong, P. (2018). Compatibility and productivity of bricklaying gangs. BSc Dissertation. Northumbria University.

Atalah, A. (2014). Comparison of Personality Traits among Estimators, Project Managers, and the Population. J. Manage. Eng., $30(2), 173-179$

Barrett, P. (2005) Euclidean Distance-Raw, Normalised, and Double-Scaled Coefficients. Available at: http://www.pbarrett.net/techpapers/euclid.pdf (Accessed 22 Aug 2019)

Barrick, M.R. and Mount, M.K. (1991). The Big-Five personality dimensions and job performance: a meta-analysis. Pers. Psychol. 44(1), 1-26.

Bowers, C.A., Pharmer, J.A. and Salas, E. (2000). When member homogeneity is needed in work teams: A meta-analysis. Small Gro. Res. 31(3), 305-327.

Boyle, G. J., Matthews, G., and Saklofske, D. H. (2008). The SAGE Handbook of personality theory and assessment. Vol 2, Personality measurement and testing. Los Angeles, California: SAGE Publications.

Brockmann, M., Clarke, L. and Winch, C. (2010). Bricklaying is more than Flemish bond: Bricklaying qualifications in Europe. Available at: http://www.academia.edu/ (Accessed 30 Aug 2018)

Bryman, A. and Cramer, D. (2005). Quantitative data analysis with SPSS Release 12 and 13: A guide for social scientists. London: Routledge.

Campion, M.A., Medsker, G.J., Higgs, A.C. (1993). Relations between work group characteristics and effectiveness implications for designing effective work groups. Pers. Psychol. 46, 823-850.

Castillo, T., Alarcon, L.F. and Pellicer, E. (2018). Influence of Organizational Characteristics on Construction Project Performance Using Corporate Social Networks. J. Manage. Eng, 34(4), 63-71.

Chamorro-Premuzic, T. (2015). Personality and individual differences. Chichester: Wiley.

Chih, Y.Y., Kiazad, K., Cheng, D., Lajom, J.A.L., Restubog, S.L.D. (2017). Feeling Positive and Productive: Role of Supervisor-Worker Relationship in Predicting Construction Workers' Performance in the Philippines. J. Constr. Eng. Manage, $143(8), 80-96$.

Childs, B.R., Weidman, J.E., Farnsworth, C.B., and Christofferson, J. P. (2017). Use of personality profile assessments in the US commercial construction industry. Intl J. of Constr Edu and Res, 13(4), 267-283.

Chitester, D.D. (1992). Model for analysing jobsite productivity. Trans. of the American Assoc. of Cost Eng., 1, C.3.1.-C.3.5. Chow, P. T., S. O. Cheung, and Y. Wa. (2015). Impact of trust and satisfaction on the commitment-withdrawal relationship. J. Manage. Eng. 31 (5), 789-796. 
Cohen, C.A. and Bailey, R. (1997). What makes teams work: Group effectiveness research from the shop floor to the executive suite. J. of Manage. 23, 239-290.

Construction Industry Institute (CII). (1990). Productivity Measurement: An introduction- Research Summary 7-1, Construction Industry Institute, Austin, TX.

Crawford, P., and Vogl, B. (2006). Measuring productivity in the construction industry. Buil. Res. and Inf. 34(3), 208-219.

Culp, G., and Smith, A. (2001). Understanding psychological type to improve project team performance. J. Manage. Eng., 17(1), 24-33.

Dineen, B. R., Ash, S. R., and Noe, R. A. (2002). A Web of applicant attraction: Person-organization fit in the context of Webbased recruitment. J. Appl. Psychol. 87 (4), 723-734.

Domigues Quelhas, A., Filho, J.R.F., Vieira Neto, J., Pererira, V. (2019). Model to Measure Adherence of Culture, Climate, and Organizational Behavior in a Construction Company, J. Manage. Eng., 35(4), 25-37.

Dozzi, S.P. and AbouRizk, S. (1993). Productivity in construction. Institute for Research in Construction, National Research Council, Ottawa, ON.

Festinger, L. (1954). A theory of social comparison processes. Human Relations, 7, 117-140.

Florez, L. (2017). Crew Allocation System for the Masonry Industry. Comp.-Aided Civil and Infr. Eng., 32 (6), 874-889.

Florez, L. and Cortissoz, J.C. (2016). Defining a Mathematical Function for Labor Productivity in Masonry Construction: A Case Study. Procedia Engineering, 164, 42-48.

Furnham, A., Petrides, K.V., Tsaousis, I., Pappas, K. and Garrod, D. (2005). A cross-cultural investigation into the relationships between personality traits and work values. J. of Psychol, 139(1), 5-32.

Gatti, U.C., Migliaccio, G.C., Bogus, S.M., and Schneider, S. (2014). An exploratory study of the relationship between construction workforce physical strain and task level productivity. Constr. Manage. Econ., 32(6), 548-564.

Goldberg, L. R. (1990). The development of markers for the Big-Five factor structure. Psychol. Assess. 4, $26-42$.

Gosling, S.D., Rentfrow, P.J. and Swann Jr, W.B. (2003). A very brief measure of the Big-Five personality domains. J. of Res. in Pers., 37(6), 504-528.

Gregory, R. J. (2015). Psychological testing: history, principles, and applications. Harlow: Pearson.

Halfill, T., Sundstrom, E., Lahner, J., Calderone, W., and Nielsen, T.M. (2005). Group personality composition and group effectiveness. An integrative reiview of empirical research. Small Gro. Res., 36(1), 83-105.

Hesse-Biber, S.N., and Leavy, P. (2006). The practice of qualitative research. Thousand Oaks, CA: Sage Publications. Hinton, P. R., McMurray, I. and Brownlow, C. (2014). SPSS explained. London: Routledge, Taylor \& Francis Group. 
Hofmann, D.A., and Jones, L. (2005). Leadership, collective personality and performance. J. Appl. Psychol., 90(3), 509-522.

Hogan, J. and Holland, B. (2003). Using theory to evaluate personality and job-performance relations: A socioanalytic perspective. J. Appl. Psychol., 88(1), 100-112.

Jaynes, E.T. (2003). Probability Theory: The Logic of Science, Cambridge University Press.

John, O.P. (1990). The big-five factor taxonomy: dimensions of personality in the natural language and questionnaires. In Handbook of personality: Theory and research, 66-100. New York: Guilford.

John, O.P. and Srivastava, S. (1999). The Big-Five trait taxonomy: History, measurement, and theoretical perspectives. In Handbook of personality: theory and research. 2nd Ed. New York: Guilford.

John, O.P., Donahue, E.M. and Kentle, R.L. (1991). The Big-Five Inventory-Versions 4a and 54'. Berkeley. CA: University of California, Berkeley, Institute of Personality and Social Research.

Kazaz, A., Manisali, E. and Ulubeyli, S. (2008). Effect of basic motivational factors on construction workforce productivity in Turkey. J. of Civil Eng. and Manage. 14(2), 95-106.

Kelly, E.L., and Conley, J.J. (1987). Personality and compatibility: a prospective analysis of marital stability and marital satisfaction. J. Pers. Soc. Psychol. 52(1), 27-40.

Kenley, R. (2014). Productivity improvement in the construction process, Constr. Manage. Econ., 32(6), 489-494.

Kichuk, S.L. and Wiesner, W.H. (1997). The Big-Five personality factors and team performance: implications for selecting successful product design teams. J. of Eng. and Tech. Manage., 14(3-4), 195-221.

Kristof-Brown, A. L., and Stevens, C. K. (2001). Goal congruence in project teams: Does the fit between members' personal mastery and performance goals matter? J. Appl. Psychol., 86, 1083-1095.

Kristof-Brown, A. L., Zimmerman, R. D., and Johnson, D. J. (2005). Consequences of individuals' fit at work: A meta-analysis of person-job, person-organization, person-group and person-supervisor fit. Pers. Psychol. 58, $281-342$.

Kwofie, T.E., Alhassan, A., Botchway, E., and Afranie, I. (2015). Factors contributing towards the effectiveness of construction project teams. Intl. J. of Constr Manage, 15(2), 170-178.

Landau, S. and Everitt, B. S. (2004). A Handbook of Statistical Analyses using SPSS. London: Chapman.

Li, Y., Lu, Y., Cui, Q., Han, Y. (2019). Organizational Behavior in Megaprojects: Integrative Review and Directions for Future Research. J. Manage. Eng, 35 (4), 1887-1898.

Liu, J., Wang, Z., Skitmore, M., and Yan, L. (2019). How Contractor Behavior Affects Engineering Project Value-Added Performance. J. Manage. Eng, 35 (4), 1943-1997. 
Loosemore, M. (2014). Improving construction productivity: a subcontractor's perspective. Eng., Constr. and Arch. Manage., 21(3), 245-260.

Maltby, J., Day, L., and Macaskill, A. (2017). Personality, individual differences, and intelligence. New York: Pearson. McCrae, R.R. and Costa, P.T. (1989). Reinterpreting the Myers-Briggs type indicator from the perspective of the five-factor model of personality. J. of Pers., 57(1), 17-40.

McCrae, R.R. and John, O.P. (1992). An introduction to the five-factor model and its applications. J. of Pers., 60, 175-215. McCrae, R.R., and Costa, P.T. (1997). Personality trait structure as a human universal. Ame. Psychol. 52, 509-516.

Meikle, J and Best, R. (2015). Measuring construction: prices, output and productivity. London: Routledge.

Mitropoulos, P. and Memarian, B. (2012). Team processes and safety of workers: Cognitive, affective, and behavioral processes of construction crews. J. Constr. Eng. Manage., 138(10), 1181-1191.

Mohammed S., Mathieu, J.E. and Bartlett, L.B. (2002). Technical administrative task performance, leadership task performance and contextual performance: considering the influence of team and task related composition variables. J. of Org. Behav. 23, 795-814.

Mohammed, S., and Angell, L.C. (2003). Personality Heterogeneity in Teams: Which Differences Make a Difference for Team Performance? Small Gro. Res. 34(6), 651-677.

Molleman, E., Nauta, A., and Jehn, K. A. (2004). Person-job fit applied to teamwork: A multilevel approach. Small Gro. Res. $35,515-539$.

Naoum, S.G. (2016). Factors influencing labor productivity on construction sites: a state-of-the-art literature review and a survey. Int. J. of Prod. and Perf. Manage. 65(3), 401-421.

Nasir, H., Ahmed, H., Haas, C., and Goodrum, P.M. (2014). An analysis of construction productivity differences between Canada and the United States. Constr. Manage. Econ., 32(6), 595-607.

Neuman, G.A., Wagner, S.H., and Christiansen, N.D. (1999). The relationship between work-team personality composition and the job performance in teams. Group \& Org. Pscyhol., New Orleans LA.

Peeters, M.A., Van Tuijl, H.F., Rutte, C.G. and Reymen, I.M. (2006). Personality and team performance: a meta-analysis. Europ. J. of Pers., 20(5), 377-396.

Raoufi, M., and Robinson Fayek, A. (2018). Key moderators of the relationship between construction crew motivation and performance. J. Constr. Eng. Manage., 144(6), 936-964. 
Regans, R., Zuckerman, E., and McEvily, B. (2004). How to make the team: social network demography as criteria for designing effective teams. Admin Sci Quart, 49(1), 101-125.

Reilly, R.R., Lynn, G.S. and Aronson, Z.H. (2002). The role of personality in new product development team performance. J. of Eng. and Technology Manage., 19(1), 39-58.

Salvendy, G. (2001). Handbook of Industrial Engineering: Technology and Operations Management, 3rd Ed, John Wiley \& Sons, Hoboken, NJ.

Sanders, S.R., and Thomas, H.R. (1991). Factors affecting masonry labor productivity J. Constr. Eng. Manage., 117(4), 626643.

Shehata, M.E. and El-Gohary, K.M. (2011). Towards improving construction labor productivity and projects’ performance. Alexandria Eng. J. 50(4), 321-330.

Shuck, B., and Reio, T. G. (2013). Employee Engagement and Well-Being: A Moderation Model and Implications for Practice. J. of Leader. \& Org. Stud. 21(1), 43-58.

Sprauer, W., Blackburn, T., Blessner, P., and Olson, B.A. (2016). Self-Organization and Sense-Making in Architect-Engineer Design Teams: Leveraging Health Care's Approach to Managing Complex Adaptive Systems. J. Manage. Eng, 32(2), 134144.

Sundstrom, E., De Meuse Kp, Futrell D. (1990). Work teams: Applications and effectiveness. Ame. Psychol, 45,120-133.

Thomas, A.V. and Sudhakumar, J. (2013). Critical analysis of the key factors affecting construction labour productivity-An Indian Perspective. Int. J. of Constr. Manage. 13(4), 103-125.

Thomas, H.R. (1991). Labor productivity and work sampling: the bottom line. J. Constr. Eng. Manage. 117(3), $423-444$.

Thomas, H.R. and Zavrski, I. (1999). Construction baseline productivity: Theory and practice. J. Constr. Eng. Manage. 125(5), $295-303$.

Thomas, H.R., Maloney, W.F., Horner, R.M.W., Smith, G.R., Handa, V.K. and Sanders, S.R. (1990). Modeling construction labor productivity. J. Constr. Eng. Manage. 116(4), 705-726.

Tziner, A. (1985). How team composition affects task performance: Some theoretical insights. Psychol Rep. 57(3), 1111-1119. Van Vianen A.E.M. and De Dreu, C.K.W. (2001). Personality in teams: its realtions to social cohesion, task cohesion, and team performance. Europ. J. of Work and Org. Psychol. 10, 97-120.

Varvel, T., Adams, S.G., Pridie, S.J., and Ruiz Ulloa, B.C. (2004). Team Effectiveness and Individual Myers-Briggs Personality Dimensions. J. Manage. Eng. 20(4), 141-146.

Vrbik, J (2005). Population moments of sampling distributions. Computational Stat. 20 (4), 611-621. 
Wang, Y., Hu, N., Zuo, J., and Rameezdeen, R. (2020). Project Management Personnel Turnover in Public Sector Construction Organizations in China. J. Manage. Eng, 36(2), 742-754.

Witte, E., and Davis, J.H. (1996). Understanding group behaviour: small group processes and interpersonal relations. Laurence Erlbaum Associates Inc, New York.

Wu, G., Zhao, X., and Zuo, J. (2017). Relationship between Project's Added Value and the Trust-Conflict Interaction among Project Teams. J. Manage. Eng, 33(4), 597-609.

Table 1. Compatibility profiles of masonry crews

\begin{tabular}{|c|c|c|c|c|c|c|c|}
\hline Crew & Masons & $\mathrm{O}$ & $\mathrm{C}$ & $\mathrm{E}$ & $\mathrm{A}$ & $\mathrm{N}$ & Compatibility \\
\hline \multirow{2}{*}{1} & $\mathrm{~m} 1$ & 4.33 & 4.44 & 4.67 & 4.89 & 3.33 & \multirow{2}{*}{0.55} \\
\hline & $\mathrm{m} 2$ & 3.60 & 5.07 & 3.46 & 5.85 & 3.46 & \\
\hline \multirow[t]{2}{*}{2} & $\mathrm{~m} 3$ & 4.63 & 5.59 & 4.92 & 6.44 & 3.88 & \multirow[t]{2}{*}{0.39} \\
\hline & $\mathrm{m} 4$ & 4.27 & 3.74 & 3.38 & 3.93 & 4.25 & \\
\hline \multirow[t]{2}{*}{3} & $\mathrm{~m} 5$ & 4.83 & 5.30 & 4.17 & 5.37 & 3.58 & \multirow[t]{2}{*}{0.55} \\
\hline & m6 & 4.97 & 6.33 & 5.04 & 6.19 & 2.71 & \\
\hline \multirow[t]{2}{*}{4} & $\mathrm{~m} 7$ & 4.20 & 4.11 & 4.25 & 4.78 & 3.25 & \multirow[t]{2}{*}{0.65} \\
\hline & $\mathrm{m} 8$ & 4.13 & 4.52 & 4.54 & 3.85 & 3.83 & \\
\hline \multirow{2}{*}{5} & $\mathrm{~m} 9$ & 4.37 & 6.11 & 5.04 & 6.00 & 3.00 & \multirow{2}{*}{0.41} \\
\hline & $\mathrm{m} 10$ & 3.97 & 5.37 & 2.04 & 5.48 & 3.46 & \\
\hline \multirow[t]{2}{*}{6} & $\mathrm{~m} 11$ & 3.57 & 4.78 & 4.04 & 4.00 & 4.17 & \multirow[t]{2}{*}{0.43} \\
\hline & $\mathrm{m} 12$ & 4.80 & 5.78 & 4.75 & 5.44 & 2.25 & \\
\hline \multirow[t]{2}{*}{7} & $\mathrm{~m} 13$ & 4.50 & 5.22 & 5.00 & 5.67 & 3.13 & \multirow[t]{2}{*}{0.59} \\
\hline & $\mathrm{m} 14$ & 4.00 & 5.00 & 5.63 & 4.33 & 3.25 & \\
\hline \multirow[t]{2}{*}{8} & $\mathrm{~m} 15$ & 6.33 & 6.67 & 5.42 & 6.30 & 2.00 & \multirow[t]{2}{*}{0.54} \\
\hline & $\mathrm{m} 16$ & 4.80 & 5.78 & 5.25 & 5.78 & 2.38 & \\
\hline \multirow[t]{2}{*}{9} & $\mathrm{~m} 17$ & 4.60 & 5.67 & 5.13 & 5.56 & 3.13 & \multirow[t]{2}{*}{0.63} \\
\hline & $\mathrm{m} 18$ & 5.30 & 5.68 & 4.13 & 5.11 & 3.13 & \\
\hline \multirow[t]{2}{*}{10} & m19 & 4.30 & 4.89 & 4.25 & 6.00 & 3.79 & \multirow[t]{2}{*}{0.59} \\
\hline & $\mathrm{m} 20$ & 4.53 & 6.15 & 4.96 & 6.15 & 3.33 & \\
\hline \multirow[t]{2}{*}{11} & $\mathrm{~m} 21$ & 6.10 & 6.11 & 6.00 & 6.22 & 1.75 & \multirow[t]{2}{*}{0.46} \\
\hline & $\mathrm{m} 22$ & 4.90 & 5.56 & 6.25 & 5.67 & 3.88 & \\
\hline \multirow[t]{2}{*}{12} & $\mathrm{~m} 23$ & 4.67 & 4.78 & 4.17 & 4.78 & 4.42 & \multirow[t]{2}{*}{0.46} \\
\hline & $\mathrm{m} 24$ & 3.20 & 5.85 & 5.71 & 5.22 & 3.54 & \\
\hline \multirow[t]{2}{*}{13} & $\mathrm{~m} 25$ & 5.53 & 6.11 & 6.50 & 3.30 & 3.21 & \multirow[t]{2}{*}{0.39} \\
\hline & $\mathrm{m} 26$ & 4.10 & 6.11 & 5.13 & 5.78 & 1.63 & \\
\hline \multirow[t]{2}{*}{14} & $\mathrm{~m} 27$ & 4.90 & 6.11 & 2.13 & 5.56 & 3.13 & \multirow[t]{2}{*}{0.55} \\
\hline & $\mathrm{m} 28$ & 5.20 & 5.22 & 3.54 & 5.89 & 3.63 & \\
\hline 15 & $\mathrm{~m} 22$ & 4.90 & 5.56 & 6.25 & 5.67 & 3.88 & 0.46 \\
\hline & $\mathrm{m} 25$ & 5.53 & 6.11 & 6.50 & 3.30 & 3.21 & \\
\hline 16 & $\mathrm{~m} 21$ & 6.10 & 6.11 & 6.00 & 6.22 & 1.75 & 0.50 \\
\hline & $\mathrm{m} 26$ & 4.10 & 6.11 & 5.13 & 5.78 & 1.63 & \\
\hline & $\mathrm{m} 23$ & 4.67 & 4.78 & 4.17 & 4.78 & 4.42 & \\
\hline
\end{tabular}




\begin{tabular}{cccccccc}
17 & $\mathrm{~m} 28$ & 5.20 & 5.22 & 3.54 & 5.89 & 3.63 & 0.57 \\
18 & $\mathrm{~m} 9$ & 4.37 & 6.11 & 5.04 & 6.00 & 3.00 & 0.76 \\
& $\mathrm{~m} 17$ & 4.60 & 5.67 & 5.13 & 5.56 & 3.13 & \\
19 & $\mathrm{~m} 24$ & 3.20 & 5.85 & 5.17 & 5.22 & 3.54 & 0.36 \\
& $\mathrm{~m} 27$ & 4.90 & 6.11 & 2.13 & 5.56 & 3.13 & \\
20 & $\mathrm{~m} 12$ & 4.80 & 5.78 & 4.75 & 5.44 & 2.25 & 0.78 \\
& $\mathrm{~m} 16$ & 4.80 & 5.78 & 5.25 & 5.78 & 2.38 & \\
\hline
\end{tabular}

Table 2. Productivity of the crews

\begin{tabular}{ccccc}
\hline Crew & Masons & Productive time $(\mathrm{hr})$ & Output $\left(\mathrm{m}^{2}\right)$ & Productivity $\left(\mathrm{m}^{2} / \mathrm{hr}\right)$ \\
\hline 1 & $\mathrm{~m} 1, \mathrm{~m} 2$ & 226 & 309 & 1.36 \\
2 & $\mathrm{~m} 3, \mathrm{~m} 4$ & 234 & 226 & 0.96 \\
3 & $\mathrm{~m} 5, \mathrm{~m} 6$ & 230 & 283 & 1.23 \\
4 & $\mathrm{~m} 7, \mathrm{~m} 8$ & 226 & 279 & 1.23 \\
5 & $\mathrm{~m} 9, \mathrm{~m} 10$ & 231 & 257 & 1.11 \\
6 & $\mathrm{~m} 11, \mathrm{~m} 12$ & 236 & 209 & 0.88 \\
7 & $\mathrm{~m} 13, \mathrm{~m} 14$ & 232 & 276 & 1.19 \\
8 & $\mathrm{~m} 15, \mathrm{~m} 16$ & 238 & 278 & 1.17 \\
9 & $\mathrm{~m} 17, \mathrm{~m} 18$ & 230 & 341 & 1.48 \\
10 & $\mathrm{~m} 19, \mathrm{~m} 20$ & 236 & 330 & 1.40 \\
11 & $\mathrm{~m} 21, \mathrm{~m} 22$ & 225 & 299 & 1.33 \\
12 & $\mathrm{~m} 23, \mathrm{~m} 24$ & 221 & 228 & 1.03 \\
13 & $\mathrm{~m} 25, \mathrm{~m} 26$ & 224 & 264 & 1.18 \\
14 & $\mathrm{~m} 27, \mathrm{~m} 28$ & 229 & 281 & 1.23 \\
15 & $\mathrm{~m} 22, \mathrm{~m} 25$ & 230 & 229 & 0.99 \\
16 & $\mathrm{~m} 21, \mathrm{~m} 26$ & 234 & 249 & 1.06 \\
17 & $\mathrm{~m} 23, \mathrm{~m} 28$ & 231 & 268 & 1.16 \\
18 & $\mathrm{~m} 9, \mathrm{~m} 17$ & 238 & 356 & 1.50 \\
19 & $\mathrm{~m} 24, \mathrm{~m} 27$ & 231 & 220 & 0.95 \\
20 & $\mathrm{~m} 12, \mathrm{~m} 16$ & 226 & 292 & 1.30 \\
\hline
\end{tabular}

Table 3. Descriptive statistics for the big-five inventory (BFI)

\begin{tabular}{lcccc}
\hline \multicolumn{1}{c}{ Factor } & $\begin{array}{c}\text { Mean } \\
\text { (M) }\end{array}$ & $\begin{array}{c}\text { Standard } \\
\text { deviation } \\
\text { (SD) }\end{array}$ & $\begin{array}{c}\text { Cronbach's } \\
\text { alpha }\end{array}$ & $\begin{array}{c}\text { Standardised } \\
\text { Cronbach's alpha }\end{array}$ \\
\hline Openness (O) & 4.62 & 1.45 & 0.68 & 0.71 \\
Conscientiousness (C) & 5.43 & 1.39 & 0.69 & 0.72 \\
Extraversion (E) & 4.63 & 1.56 & 0.85 & 0.85 \\
Agreeableness (A) & 5.34 & 1.48 & 0.75 & 0.75 \\
Neuroticism (N) & 3.24 & 1.50 & 0.64 & 0.64 \\
\hline Mean & 4.69 & 1.66 & 0.70 & 0.71 \\
\hline
\end{tabular}


Table 4. Spearman's correlation coefficients between the big five factors

\begin{tabular}{lccccc}
\hline \multicolumn{1}{c}{ Factor } & $\mathrm{E}$ & $\mathrm{A}$ & $\mathrm{C}$ & $\mathrm{N}$ & $\mathrm{O}$ \\
\hline Extraversion (E) & 1.000 & & & & \\
Agreeableness (A) & 0.204 & 1.000 & & & \\
Conscientousness (C) & $0.505^{* *}$ & $0.575^{* *}$ & 1.000 & & \\
Neuroticism (N) & $-0.438^{* *}$ & $-0.373^{* *}$ & $-0.686^{* *}$ & 1.000 & \\
Openness (O) & 0.255 & $0.340^{*}$ & $0.507^{* *}$ & $-0.360^{*}$ & 1.000 \\
\hline
\end{tabular}

**Corr is significant at the 0.01 level (one-tailed); *Corr is significant at the 0.05 level (one-tailed)

Table 5. Correlation matrix between compatibility and productivity

\begin{tabular}{llcc}
\hline Spearman's rho & & Compatibility & Productivity \\
\hline Compatibility & $\begin{array}{l}\text { Correlation } \\
\text { coefficient }\end{array}$ & 1.000 & $0.758^{* *}$ \\
& Sig (1-tailed) & 0.0 & 0.000 \\
Productivity & $\begin{array}{l}\text { Correlation } \\
\text { coefficient }\end{array}$ & $0.758^{* *}$ & 1.000 \\
& Sig (1-tailed) & 0.000 & 0.0 \\
\hline **Corr is significant at the 0.01 level (one-tailed) & & \\
\hline
\end{tabular}

Appendix A

\begin{tabular}{|c|c|c|c|c|c|c|}
\hline Dimension & Factor & Mean & SD & $\begin{array}{c}\text { Corrected } \\
\text { item-total } \\
\text { corr. }\end{array}$ & $\begin{array}{c}\text { Squared } \\
\text { multiple } \\
\text { corr. }\end{array}$ & $\begin{array}{c}\text { Cronbach's } \\
\alpha \text { if item } \\
\text { deleted }\end{array}$ \\
\hline \multirow{8}{*}{ 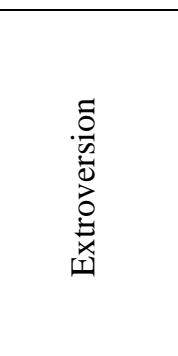 } & Talkative & 4.76 & 1.38 & 0.76 & 0.69 & 0.81 \\
\hline & Reserved & 4.10 & 1.65 & 0.38 & 0.48 & 0.86 \\
\hline & Full of energy & 4.93 & 1.42 & 0.50 & 0.65 & 0.84 \\
\hline & Generates enthusiasm & 4.87 & 1.53 & 0.62 & 0.83 & 0.82 \\
\hline & Quiet & 4.04 & 1.55 & 0.67 & 0.70 & 0.82 \\
\hline & Assertive & 4.83 & 0.98 & 0.33 & 0.45 & 0.85 \\
\hline & Shy, inhibited & 4.36 & 2.04 & 0.72 & 0.84 & 0.81 \\
\hline & Outgoing, sociable & 5.18 & 1.53 & 0.72 & 0.84 & 0.81 \\
\hline \multirow{9}{*}{ 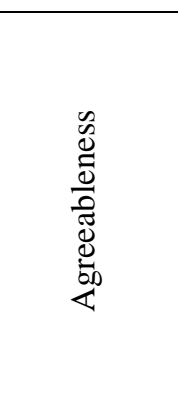 } & Finds fault with others & 4.61 & 1.63 & 0.48 & 0.59 & 0.71 \\
\hline & Helpful, unselfish with others & 5.83 & 1.16 & 0.57 & 0.58 & 0.71 \\
\hline & Likes to cooperate with others & 5.80 & 1.12 & 0.25 & 0.51 & 0.75 \\
\hline & Quarrelsomeness & 5.26 & 1.72 & 0.59 & 0.55 & 0.69 \\
\hline & Forgiving & 5.14 & 1.36 & 0.54 & 0.49 & 0.71 \\
\hline & Trusting & 5.92 & 1.00 & 0.32 & 0.44 & 0.74 \\
\hline & Cold and aloof & 4.81 & 1.74 & 0.27 & 0.21 & 0.76 \\
\hline & Rude to others & 5.17 & 1.69 & 0.51 & 0.42 & 0.71 \\
\hline & Considerate and kind & 5.56 & 1.26 & 0.36 & 0.72 & 0.74 \\
\hline \multirow{5}{*}{ 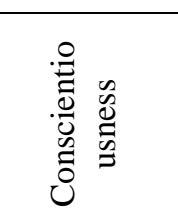 } & Does a thorough job & 6.01 & 1.01 & 0.57 & 0.69 & 0.63 \\
\hline & Somewhat careless & 5.23 & 1.24 & 0.06 & 0.53 & 0.72 \\
\hline & A reliable worker & 6.10 & 1.03 & 0.50 & 0.71 & 0.64 \\
\hline & Disorganized & 4.64 & 1.71 & 0.28 & 0.50 & 0.69 \\
\hline & Lazy & 5.52 & 1.73 & 0.42 & 0.54 & 0.65 \\
\hline
\end{tabular}




\begin{tabular}{|c|c|c|c|c|c|c|}
\hline & Perseveres until the task is finished & 5.66 & 1.25 & 0.27 & 0.32 & 0.68 \\
\hline & Does things efficiently & 5.50 & 1.07 & 0.49 & 0.58 & 0.64 \\
\hline & Makes plans and follows through & 5.60 & 1.04 & 0.64 & 0.57 & 0.62 \\
\hline & Easily distracted & 4.65 & 1.52 & 0.30 & 0.64 & 0.68 \\
\hline \multirow{8}{*}{$\begin{array}{l}\tilde{n} \\
0 \\
0 \\
0 \\
0 \\
0 \\
z \\
z\end{array}$} & Nervous & 2.88 & 1.36 & 0.39 & 0.39 & 0.46 \\
\hline & Depressed, blue & 2.85 & 1.72 & 0.25 & 0.37 & 0.51 \\
\hline & Relaxed, handles stress well & 2.83 & 1.40 & 0.37 & 0.38 & 0.47 \\
\hline & Tense & 3.45 & 1.39 & 0.46 & 0.28 & 0.44 \\
\hline & Moody & 3.99 & 1.53 & 0.03 & 0.16 & 0.59 \\
\hline & Worries & 3.60 & 1.62 & 0.35 & 0.32 & 0.47 \\
\hline & Emotionally stable, not easily upset & 2.99 & 1.40 & 0.24 & 0.33 & 0.51 \\
\hline & Remains calm in tense situations & 3.33 & 1.26 & 0.02 & 0.23 & 0.58 \\
\hline \multirow{10}{*}{$\begin{array}{l}\tilde{0} \\
\stackrel{0}{\Xi} \\
\tilde{\Xi} \\
\tilde{0}\end{array}$} & Original, comes up with new ideas & 4.93 & 1.23 & 0.41 & 0.54 & 0.63 \\
\hline & Curious about many different things & 5.14 & 1.23 & 0.35 & 0.32 & 0.64 \\
\hline & Ingenious, a deep thinker & 4.71 & 1.31 & 0.58 & 0.50 & 0.59 \\
\hline & Shows an active imagination & 5.18 & 1.23 & 0.57 & 0.66 & 0.60 \\
\hline & Values artistic, aesthetic experiences & 4.68 & 1.19 & 0.36 & 0.34 & 0.64 \\
\hline & Inventive & 4.89 & 1.26 & 0.20 & 0.29 & 0.67 \\
\hline & Interested in artistic pursuits & 3.95 & 1.46 & 0.48 & 0.57 & 0.61 \\
\hline & Prefers work that is routine & 3.86 & 1.79 & 0.03 & 0.41 & 0.72 \\
\hline & Likes to reflect and play with ideas & 4.81 & 1.12 & 0.55 & 0.60 & 0.61 \\
\hline & Acts sophisticated in art, music or literature & 4.00 & 1.87 & 0.09 & 0.20 & 0.71 \\
\hline
\end{tabular}

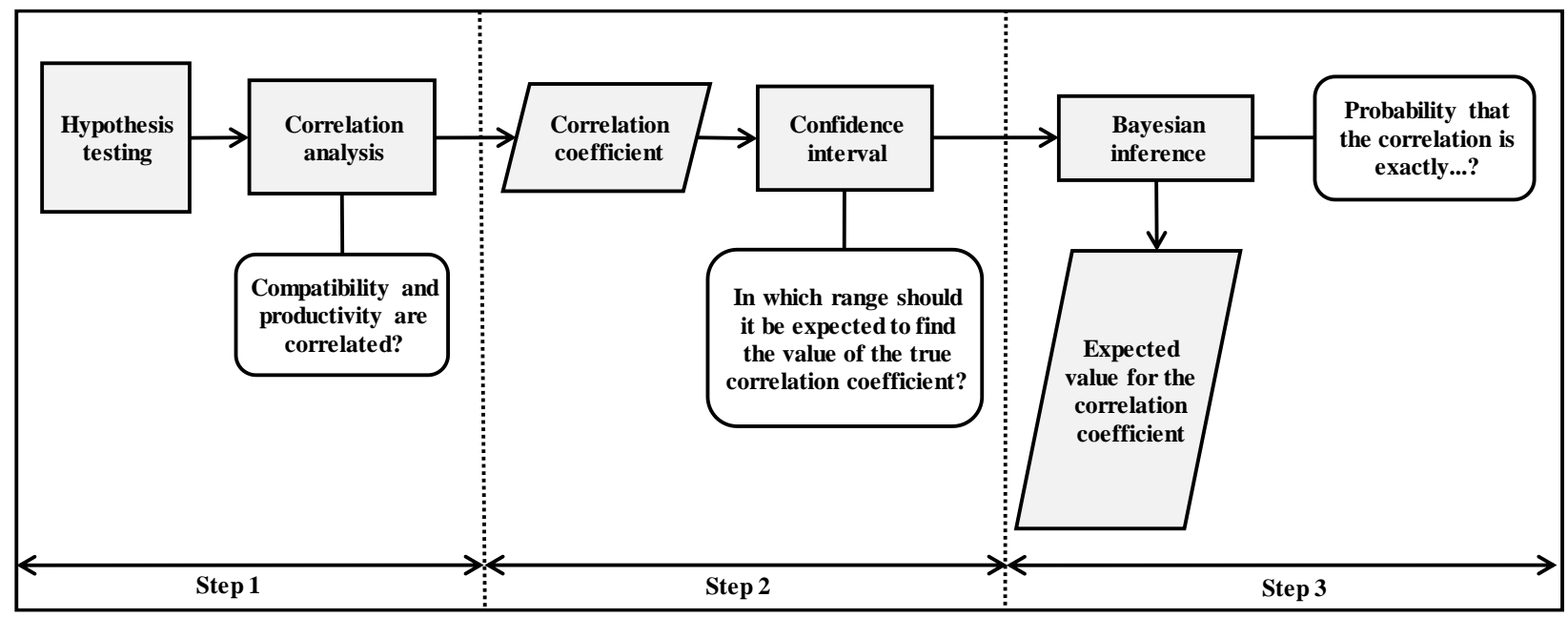

Fig 1. Statistical analyses 


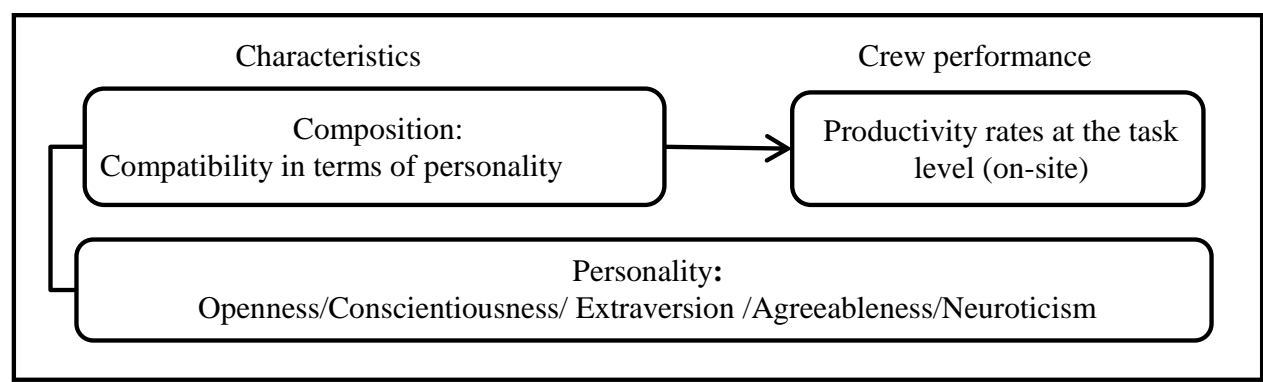

Fig 2. Relationship between personality, compatibility and productivity 